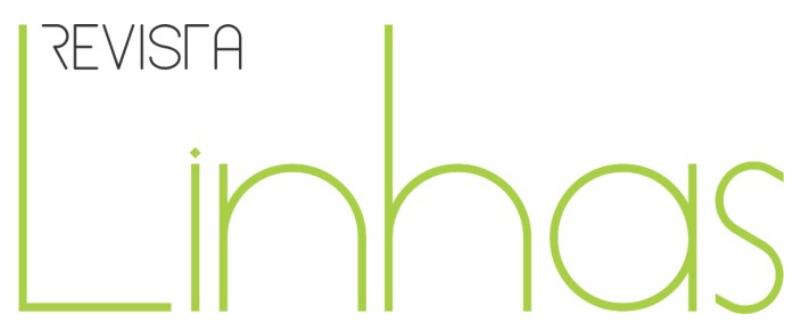

\title{
A escola elementar de Pestalozzi e Calkins: como ensinar número?
}

\begin{abstract}
Resumo
O presente texto é fruto dos primeiros passos da abordagem investigativa de doutoramento, a qual foca os processos de circulação e apropriação do método intuitivo para o ensino de Aritmética na escola elementar. De modo particular, este artigo busca desvelar o modo pelo qual o ensino de número foi proposto a partir das diretrizes do método intuitivo. Neste propósito, constituíram-se como pontos de partida as análises das fontes que são os escritos de Pestalozzi e Calkins através dos livros Cómo Gertrudis enseña a sus hijos e Primeiras Lições de Coisas, respectivamente. Interessa saber: Como se deu o ensino de número através das ideias pedagógicas sistematizadas por Pestalozzi (as quais foram apropriadas e incorporadas por Calkins na composição do seu manual pedagógico)? Na busca por resposta, o texto organizase em três tópicos. De início, faz-se uma sucinta abordagem das ideias pedagógicas pestalozzianas, realçando o modo de instruir por meio da intuição. Em seguida, o texto recai nas leituras de ambas as fontes, analisando cada proposta para o ensino de número. Por fim, discute-se as diferenças observadas nas propostas, permitindo a compreensão não só do ensino de número, mas também do modo de apropriação de Pestalozzi por Calkins.
\end{abstract}

Palavras-chave: Aritmética; Número; Pestalozzi; Calkins.

\section{Para citar este artigo:}

OLIVEIRA, Marcus Aldenisson de. A escola elementar de Pestalozzi e Calkins: como ensinar número? Revista Linhas. Florianópolis, v. 16, n. 31, p. 173 -201, maio/ago. 2015.

\author{
Marcus Aldenisson de Oliveira \\ Doutorando pelo Programa de \\ Pós-Graduação em Educação e \\ Saúde da Universidade Federal \\ de São Paulo - \\ UNIFESP/Guarulhos - Brasil
}

marcus_aldenisson@hotmail.com 


\title{
The elementary school of Pestalozzi and Calkins: how to teach number?
}

\begin{abstract}
This text is the result of the first steps of the investigative approach that focuses on doctoral processes of circulation and appropriation of intuitive method for teaching arithmetic in elementary school. In particular, this article seeks to reveal the way in which the teaching of number was proposed based on the guidelines of the intuitive method. In this way, if constituted as starting points for the analysis of the sources are the writings of Pestalozzi and Calkins through books Cómo Gertrudis enseña a sus hijos and Primeiras Lições de Coisas, respectively. Interested to know: How did the number of teaching through pedagogical ideas systematized by Pestalozzi (which were appropriated and incorporated by Calkins in the composition of its teaching manual)? In search of reply, the text is organize into three topics. Initially, it is a succinct approach to pestalozzianas pedagogical ideas, highlighting the mode of instructing through intuition. Then the text lies in the readings from both sources, analyzing each proposal for teaching number. Finally, we discuss the differences in the proposals, allowing an understanding not only the teaching of number, but also the mode of appropriation of Pestalozzi by Calkins.
\end{abstract}

Keywords: Arithmetic; Number; Pestalozzi; Calkins. 
O presente artigo resulta dos primeiros passos investigativos da pesquisa de doutoramento que se encontra em desenvolvimento ${ }^{1}$. Tal pesquisa objetiva descortinar e compreender os processos de circulação e apropriação das concepções do método intuitivo para o ensino de Aritmética em escolas brasileiras dos anos iniciais. Nesta perspectiva, caminhos estão sendo construídos almejando anunciar de que modo os postulados da pedagogia de ensino intuitivo foram provocando mudanças nos saberes elementares aritméticos. Por outro lado, sabe-se que diferentes províncias/estados brasileiros adotaram para seu sistema de instrução a pedagogia moderna dos anos finais do século XIX e início do XX. Tudo leva a crer que esses foram tempos marcados pela internacionalização da educação renovada e moderna. Para Souza (1998, p. 159), “o método intuitivo foi símbolo dessa renovação e modernização do ensino".

À luz destas reflexões, surge a seguinte indagação: em meio a essa internacionalização da pedagogia modernizadora, como o ensino de número foi proposto aos anos iniciais da escolarização?

Na busca por resposta que revele como o conceito de número foi pensado, construído e dado para ser ensinado à criança na perspectiva intuitiva, alguns referenciais foram adotados. Neste propósito, constituíram-se como pontos de partida as análises das propostas de dois personagens que marcaram aquela renovação pedagógica: Pestalozzi e Calkins. De início, o texto aborda os escritos de Johann H. Pestalozzi a partir de seu livro Cómo Gertrudis enseña a sus hijos $(1801)^{2}$. A escolha desta obra se justifica porque ela traz na sua composição princípios do método sistematizado pelo seu próprio autor. Método

\footnotetext{
${ }^{1} \mathrm{O}$ projeto de doutoramento "A circulação e apropriação do método intuitivo para o ensino de aritmética: mudanças nos saberes elementares matemáticos dos anos iniciais (1880-1960)" está sendo desenvolvido na Universidade Federal de São Paulo (UNIFESP), no Programa de Pós-Graduação em Educação e Saúde na Infância e na Adolescência. A pesquisa conta com o apoio financeiro da Fundação de Amparo à Pesquisa do Estado de São Paulo (FAPESP). Soma-se a isso a incorporação dessa pesquisa doutoral no projeto guardachuva "A Constituição dos saberes elementares Matemáticos: A Aritmética, A Geometria e o Desenho no curso primário em perspectiva histórico-comparativa, (1890-1970)", coordenado pelo Prof. Dr. Wagner Rodrigues Valente.

${ }^{2}$ Para este texto utiliza-se uma tradução espanhola feita por José Tadeu Sepúlveda, em 1889, impressa pela tipografia de Antonio M. Rebolledo. A tradução desta obra se sucedeu a pedido do então Inspetor Geral das Escolas Normais do Chile, don José Abelardo Nuñez, para de início compor a Biblioteca da Família e da Escola, na qual Nuñez era diretor. Além disso, a tradução dessa obra teve como finalidade disseminar na educação chilena os princípios e as doutrinas da pedagogia Alemã e, sobretudo, pestalozziana.
} 
esse que passou a ser chamado de intuitivo. Além disso, essa obra configura um modo de ensinar número por meio da perspectiva intuitiva. Na continuidade da análise, a obra Primeiras Lições de Coisas $(1861)^{3}$, de Norman A. Calkins, é posta à cena. Como já se sabe, este manual pedagógico tem sua composição metodológica ancorada nos princípios educacionais do método de ensino intuitivo. O que também justifica a escolha dessa obra é sua investida temática destinada para o ensino de número.

Por outra parte, isso não isenta salientar que existem trabalhos cuja temática se detém em analisar a formação do conceito de número para o ensino de Aritmética em escolas brasileiras dos anos iniciais. A exemplo, destacam-se os estudos de David Antonio da Costa $(2010)^{4}$, Wagner Rodrigues Valente $(2012)^{5}$, Nara Vilma Lima Pinheiro (2013) ${ }^{6}$. De modo mais amplo, o estudo de Marcus Aldenisson de Oliveira (2013) ${ }^{7}$, que também investigou como se deu o ensino de Aritmética a partir dos princípios do método intuitivo, tomando livros didáticos como fontes. Frente a esses estudos e a outros pesquisados, não foi possível identificar investigações que se propusessem a realizar o estudo em que ora será apresentado. Neste sentido, o presente artigo se justifica pela ausência de

\footnotetext{
${ }^{3}$ O exemplar utilizado nesta investigação data de 1886, traduzido por Rui Barbosa. Este mesmo manual de Calkins foi apresentado na Exposição Universal de Filadélfia, realizada em 1876, sendo recomendado por Ferdinand E. Buisson em seu relatório ao governo francês como a melhor coleção de lições de coisas já elaborada, motivando numerosas traduções, além da língua portuguesa, destacando-se uma versão japonesa em 1877 e duas versões para o espanhol em 1872 e 1879. A primeira edição americana desse manual é de 1861, sendo refundida e ampliada em 1870, recebendo o título de Primeiras lições de coisas e atingindo, em 1884, sua $40^{a}$ edição. As referências aqui apresentadas são da publicação de 1950, coordenada pelo Ministério da Educação e Saúde, no volume 13 das obras completas de Rui Barbosa (VALDEMARIN, 2004, p. 118).

${ }^{4}$ Estou me referindo à tese de doutoramento em Educação Matemática "A Aritmética escolar no ensino primário brasileiro (1890-1946)", defendida em 2010. Nessa, o autor tratou de forma especial das transformações ocorridas com o conceito de número, as quais puderam ser lidas em livros didáticos.

${ }^{5}$ Este autor publicou em periódico um texto intitulado "O que é número? Produção, circulação e apropriação da Matemática Moderna para crianças". O referido texto objetivou analisar o conceito de número numa perspectiva do ensino tradicional, do ensino intuitivo e do movimento comumente chamado de escolanovista. No decorrer da narrativa, Valente (2012) também tratou desse saber elementar nos ideais do Movimento da Matemática Moderna, marcado por uma psicologia escolar.

${ }^{6}$ Trata-se de uma dissertação de mestrado intitulada "Escolas de práticas pedagógicas inovadoras: intuição, escolanovismo e matemática moderna nos primeiros anos escolares", defendida em 2013. Como o próprio título revela, a autora investigou as transformações do significado do conceito de número ao longo do tempo (1880 a 1970), analisando o seu ensino em três instituições modelo para generalização de práticas pedagógicas inovadoras na cidade de São Paulo. São elas: a Escola Americana, a Escola Normal da Praça e a Escola Experimental Vera Cruz.

${ }^{7}$ Trata-se de uma dissertação de mestrado intitulada "Antônio Bandeira Trajano e o método intuitivo para o ensino de Aritmética (1879-1954)". O trabalho teve por objetivo analisar a configuração do método intuitivo presente na composição da trilogia Arithmetica de Antônio Trajano.
} 
trabalhos que analisem como ensinar número a partir da proposta intuitiva de Pestalozzi, a qual foi apropriada por Calkins.

Assim, interessa saber: Como se deu o ensino de número através das ideias pedagógicas sistematizadas por Pestalozzi (as quais foram apropriadas e incorporadas por Calkins na composição do seu manual pedagógico)? Direcionado por esta problemática, a intenção primeira deste artigo é desvelar o modo pelo qual o ensino de número foi proposto a partir das concepções pedagógicas do método de ensino intuitivo. Tendo em vista as análises dos livros supracitados, coloca-se, ainda, como segundo intento evidenciar como as ideias pedagógicas pestalozzianas foram apropriadas por Calkins, no que alude ao saber escolar elementar de número.

No diálogo com os escritos do historiador francês Roger Chartier (1990), considera-se apropriação como sendo os diferentes modos de apreender e reempregar ideias pedagógicas, bem como os sentidos que se configuraram a partir da transmissão dessas. Compreende-se, ainda, que a apropriação se caracteriza a partir dos diferentes modos que uma ideia ou uma cultura é apreendida, interpretada, (re)significada e usada nas e pelas práticas ou nas e pelas representações construídas pelos sujeitos que recepcionam aquilo em circulação. A maneira como uma ideia ou uma concepção pedagógica é adquirida e usada, revela os diferentes significados que tal ideia adquiriu. Para saber como as concepções do método intuitivo elaboradas por Pestalozzi e destinadas para o ensino de número foram apropriadas por Calkins, fez-se necessário identificar os diferentes usos e adaptações que este atribuiu para as concepções intuitivas sistematizadas por aquele. Acredito que no manual de Calkins estão presentes as relações de leituras, as interpretações, os significados e os reempregos da pedagogia pestalozziana (ou seja, as modalidades de apropriação que podem ser lidas e vistas por meio das representações construídas por (alkins no seu manual).

Percebe-se, assim, que o artigo ancora-se nos auspícios da história cultural, a qual enquanto corrente historiográfica busca compreender aquilo que é construído, representado, apropriado e praticado pelos homens. Ou seja, "a história cultural é compreendida para Chartier como o estudo dos processos com os quais os sujeitos constroem sentidos para as suas ações" (BICCAS, 2012, p. 84). Por assim entender, este 
texto é dado para ser visto, lido e compreendido pelas lentes dessa corrente historiográfica.

Neste sentido, sua escrita localiza-se numa perspectiva da História da Educação; buscando tratar dum ponto de vista de menor dimensão, a História da educação matemática; e sob uma ótica mais focalizada, abordando uma matéria da escola elementar - a Aritmética. Certo disso, o texto organiza-se em três tópicos. De início, fazse uma sucinta abordagem das ideias pedagógicas pestalozzianas, realçando o modo de instruir por meio da intuição. Em seguida, a narrativa é construída pelas leituras de ambas as fontes analisando cada proposta para o ensino de número. Por fim, discutem-se as diferenças observadas nas propostas, permitindo a compreensão não só do ensino de número, mas também do modo de apropriação de Pestalozzi por Calkins.

\section{A escola elementar e o ensino pelas coisas: uma proposta de instrução ancorada nos princípios do método intuitivo}

$\mathrm{Na}$ busca por elementos que sirvam de resposta para a indagação levantada, adota-se como referencial a travessia das ideias pedagógicas do método intuitivo, cruzando o Atlântico. De um lado do oceano, estiveram as ideias intuitivas de Johann H. Pestalozzi registradas, em partes, no livro Cómo Gertrudis enseña a sus hijos, de 1801. Do outro lado da margem, identificou-se o educador norte-americano chamado Norman A. Calkins, (re)significando e reempregando, no seu manual pedagógico Primeiras Lições de Coisas de 1861, aquelas ideias pestalozzianas. Com vista nisso, uma conclusão já pode ser apresentada antes mesmo de prosseguir com esta caminhada: as ideias, de fato, circulam cada uma com seu meio e modo particular de se propagar.

A circulação e apropriação de livros, por exemplo, dizem muito mais do que uma simples difusão e recepção. Para Darnton (1992, p. 33) “[...] existem circuitos de informação e táticas de difusão próprios do comércio de livros". Vale lembrar que para este estudo não se constituiu como foco o desvelar dos circuitos de difusão daqueles livros. Entretanto, como se almeja abordar algumas modalidades de apropriação, cumpre considerar a importância da circulação para desvelar a recepção. A exemplo, pode-se dizer que esta circularidade da ideia pedagógica do método intuitivo presente nos livros 
também acaba mostrando que houve uma tentativa de criar a unificação dos moldes educacionais aritméticos, em particular. Tentativas que, possivelmente, alcançaram e interferiram mais de perto os alunos e professores nas práticas escolares desta rubrica escolar dos anos iniciais.

Por certo que este alcance e esta interferência ocorreram com os próprios contatos dos sujeitos com a ideia em circulação, isso possibilita considerar que: a circulação das concepções pedagógicas depende daqueles que delas se apropriam e as colocam em caminhos distintos para chegar até o destinatário final. Assim sendo, conjectura-se que a disseminação dos princípios do método intuitivo para o ensino da Aritmética ocorreu através das representações construídas por aqueles que delas se apropriaram e as fizeram circularem.

Ao dialogar com A. Dupront, Chartier apontou: o que importa "[...] é a encarnação da ideia, os seus significados, o uso que dela faz" (CHARTIER, 1990, p. 48). São justamente esses significados e usos que configuram e caracterizam as maneiras de apropriação que se fazem de uma ideia e/ou concepção enraizadas nos objetos em circulação. Isto é, quando se toma como ponto de vista que qualquer utilização ou qualquer apropriação de um produto ou de uma ideia necessita considerar a importância da relação (pessoal ou social) do indivíduo ou do grupo, então alguns condicionantes são colocados em relevo, tais como: a posição social do indivíduo ou do grupo; os interesses em apropriar-se ou não de algo em circulação; os meios pelos quais ele se apropriou de algo, por meio da recepção do produto ou da ideia.

Prova da relevância destes condicionamentos é a própria ausência de interesses dos dirigentes brasileiros em traduzir a obra de Pestalozzi Cómo Gertrudis enseña a sus hijos para a língua portuguesa. Ora, se o Brasil estava investindo esforços para modernizar o seu sistema educacional em tempos da pedagogia moderna, então o que configurou a não tradução da obra de Pestalozzi já que ela também demarcou tal pedagogia? Talvez a resposta mais cabível seja a falta de interesses. Essa ausência de interesses é confirmada pela própria utilização de um exemplar traduzido pela autoridade educacional chilena. Isso nos revela que, de fato, a circulação de um produto e/ou de uma ideia está sempre dependente dos interesses daqueles que se apropriam. Neste sentido, cabe retomar a fala de Chartier ao dizer: 
Do mesmo modo que as modalidades das práticas, dos gostos e das opiniões são mais distintivas [...], as maneiras como um indivíduo ou um grupo se apropria de um motivo intelectual ou de forma cultural são mais importantes do que a distribuição estatística desse motivo ou dessa forma. (CHARTIER, 1990, p. 51)

Afinal, o que se pretende realizar tomando a obra de Pestalozzi e o manual de Calkins? Por vez, o que se almeja é analisar o modo com que cada um destes sujeitos propôs o ensino de número a partir dos princípios do método intuitivo. Frente a esta análise, busca-se identificar em que medida as ideias propaladas por Pestalozzi foram apropriadas por Calkins. Para isso, realiza-se uma leitura interna de cada um destes livros, deixando recair a atenção para o saber escolar matemático dos anos iniciais - o ensino de número.

A princípio, a análise parte da obra de Johann H. Pestalozzi Cómo Gertrudis enseña a sus hijos ${ }^{8}$, traduzida para o espanhol em $1889^{9}$. Posteriormente, a análise incide sobre o manual pedagógico do norte-americano Norman Calkins, Primeiras Lições de Coisas. Para que se inicie a reflexão acerca de ambas as obras, sugere-se antes o exercício da digressão histórica. Ela é inevitável para o que se quer saber, pois possibilita uma abordagem sucinta da historicização das ideias pedagógicas do método de ensino intuitivo. Ela é imprescindível já que a retrospectiva histórica é necessária na medida em se propõe trazer à tona profundas reflexões sobre uma temática, mas sem a busca de suas origens (RIBEIRO JÚNIOR, 1969, p. 147). Sendo assim, a narrativa a seguir aborda alguns pontos biográficos do sistematizador desse método e das suas principais ações pedagógicas em prol da instrução elementar.

Chamava-se Johann Heinrich Pestalozzi o sujeito nascido em Zurique (Suíça), em 12 de janeiro de 1746, o qual é visto como o sistematizador do método de ensino intuitivo.

\footnotetext{
${ }^{8}$ Essa obra foi publicada nos Estados Unidos em 1894 com o título How Gertrude Teaches Her Children. Seu exemplar pode ser acessado em <http://studentzone.roehampton.ac.uk/library/digital-collection/froebelarchive/gertrude/Gertrude\%2ocomplete.pdf $>$.

${ }^{9}$ Registro que não foi possível identificar exemplar dessa obra traduzida para o português. Há, no entanto, uma tradução de um livro, publicado pelo Ministério da Educação em 2010, o qual apresenta a biografia de Pestalozzi expondo a suas ideias pedagógicas. Nesse livro há uma sucinta tradução de algumas cartas que compuseram o livro Cómo Gertrudis enseña a sus hijos. O referido livro está acessível no site <http://www.sema.edu.br/editor/fama/livros/historia_educacao/36_jo_pe.pdf >.
} 
Aos 81 anos Pestalozzi morre, deixando um legado educacional que até hoje está nos grandes centros de construção do conhecimento científico e educativo. Esta herança educacional foi produzida em locais e em momentos distintos. O pedagogo suíço instalou o centro educativo de nome Neuhof (1770-1780), em Argóvia, destinado para a educação de meninos pobres que também trabalhavam na fiação e tecelagem de algodão. Tempos depois, Pestalozzi transformou o castelo de Yverdun, em Neufchâtel, na Suíça Francesa, num centro de experimentação e de construção das suas ideias educacionais.

Posteriormente, já no orfanato de Stans, o pedagogista continuou desenvolvendo com os órfãos as novas práticas educativas formadas nos outros centros educativos sempre imbricando instrução com o trabalho manual. Ou seja, a atividade prática também fazia parte da instrução elementar. "As duas principais instituições que lhe deram fama foram o instituto em Burgdorf, de 1800 a 1804, e um outro semelhante em Yverdun, de 1805 a 1825" (EBY, 1978, p. 379). O suíço enxergava a atividade na educação como sendo uma das melhores ferramentas para que a criança pudesse mostrar toda a sua potencialidade. Para Eby (1978), cada centro de educação fundado por Pestalozzi foi uma “escola experimental”.

As ideias pedagógicas construídas e experimentadas nos seus centros educacionais foram sistematizadas e publicadas através de livros: Leonardo e Gertrudes (1781); Como Gertrudes ensina seus filhos (1801); O canto do Cisne (1827); dentre outros. Este último, por exemplo, é um livro que contém traços biográficos e reflexões teóricas da sua proposta pedagógica. Suas ideias obtiveram grande repercussão na educação, tendo a pretensão do surgimento de uma pedagogia alicerçada na capacidade e no espírito de curiosidade da criança. Para ele, o aprendiz não adquiria conhecimento se esse não fosse aliado às atividades práticas. Por certo disso, ele passou a defender a necessidade da criança possuir uma emancipação para aprender. Mas este ato emancipador só se tornaria real na medida em que toda ação fosse praticada pelas mãos dos interessados, ou seja, pelas iniciativas das próprias crianças. Essa pedagogia demarca, assim, um rompimento com a vertente da pedagogia em execução, que grosso modo se resumia num ensino decorado - chamado por muitos de tradicional. Tudo indica que este tipo de ensino, o decorado, entra em desuso no espaço escolar com o surgimento da pedagogia de ensino intuitivo, cuja característica básica era oferecer dados sensíveis à 
percepção dos alunos. Nesta vaga pedagógica moderna, o conhecimento era adquirido mediante a ação, isto é, a atividade do sujeito no mundo exterior acompanhado pelas transformações da natureza.

O método chamado de intuitivo pode ser resumido através das seguintes palavras: experiências dos sentidos. Entretanto, vale dizer ainda que não é qualquer tipo de experiência, mas sim aquela que estimula e produz a curiosidade da criança. Experiência que leva a criança a fazer uso dos sentidos a fim de explorar ao máximo suas faculdades, tais como: a de intuir; a de refletir; a de comparar; a de medir; e a de desenvolver a percepção. De acordo com os postulados do método intuitivo, quando tais experiências ocorrem, a aquisição do conhecimento é mediada pela própria curiosidade da criança; isto é, pelo seu espírito natural do querer saber, de querer aprender. Trata-se de uma metodologia que, quando possível, direciona o ensino pondo a criança em contato direto com aquilo que a rodeia. É experimentando cada representação das coisas, de modo sensível/perceptivo/intuitivo, que a criança aprende a significação e a utilidade dos objetos. Percebe-se que as bases de sustentação desse método eram: clareza no experimentar e precisão no pensar. Mas, como apontou Pestalozzi, "tudo depende de la psicologia de la forma de la enseñanza" (PESTALOZZI, 1889, p. 36).

As ideias pedagógicas intuitivas sistematizadas pelo educador suíço surgiram, em grande parte, quando ele educava as crianças pobres que viviam nos seus centros educativos. "Era o propósito de Pestalozzi elevar o povo dessa degradação até o nível de humanidade" (EBY, 1978, p. 383). Pestalozzi defendia o princípio de que sem o desenvolvimento das capacidades de uma criança, todos os outros direitos são inúteis e ridículos (EBY, 1978). As referidas capacidades eram aquelas que são naturais do espírito infantil: imaginar, comparar, raciocinar, perceber, julgar, observar, tocar, cheirar, degustar, ouvir, dentre outras faculdades que se desenvolvem quando estimuladas. Com vista nisso, Pestalozzi elegeu princípios que norteariam a sua proposta de ensino. Alguns desses princípios foram:

1. Primeiro, toda a verdadeira reforma deve começar com o indivíduo e não com a sociedade. [...];

2. Segundo, o indivíduo só pode ser elevado dando-lhe poder de se tornar auto-suficiente. [...] o melhor serviço que a sociedade pode 
prestar para o indivíduo é ensiná-lo, primeiro, a respeitar-se, e segundo, a amparar a si mesmo;

3. Terceiro, o único meio de atingir o fim desejado é através do desenvolvimento. As sementes de ação independente, latentes em toda criança, estão, apenas, esperando uma oportunidade de crescer. A educação deve oferecer a oportunidade para este crescer. (EBY, 1978, p. 383-384)

A formação da criança seria mediada de acordo com cada um desses princípios. Por outro lado, é importante assinalar que Pestalozzi buscou, com sua pedagogia infantil, descobrir como as crianças se desenvolviam, acompanhando seu ritmo de aquisição de conhecimento. Segundo Eby (1978, p. 384), "Pestalozzi afirmava que o organismo tem três aspectos básicos". O primeiro é o aspecto intelectual, que se desenvolve quando a criança está em contato com o ambiente, pois as coisas emitem impressões sensórias que ela experimenta. O segundo é o aspecto físico, desenvolvido quando a criança está em atividades motoras na natureza, lidando com objetos. Por último, tem-se o aspecto moral e religioso, que é conduzido através da relação da criança com outras e com o Criador. Com esses três aspectos funcionando em harmonia, a criança adquire a sua formação; deste modo, ela desenvolve as suas capacidades intelectuais, adquire habilidades na aplicação do seu conhecimento e, o mais importante, desempenha atividades construtivas de modo a aprender produzindo/praticando/fazendo.

Percebe-se que a maneira metodológica da instrução elementar proposta pelo pedagogista suíço contou com o auxílio de objetos. Ele defendia a ideia de que a partir da observação, manipulação e experimentação das coisas a criança iria construir conceitos claros. Com isso, a arte da instrução elementar pestalozziana estaria presente também na seleção dos objetos adequados para a observação ativa. Sendo assim, Pestalozzi desenvolveu seu sistema de lições de coisas. Tudo leva a crer que ele tenha sido o personagem principal que inaugurou uma nova organização metodológica no interior do espaço escolar. Tal organização certamente esteve dependente da operacionalização das coisas nas lições. Esta operacionalização possibilitava que as coisas auxiliassem na transmissão do saber escolar. Segundo Eby (1978, p. 386), "Pestalozzi esforçou-se para elaborar um sistema de instrução intelectual geral, [...]. Como conseqüência [sic], continuou buscando uma oportunidade para favorecer esse aspecto construtivo da natureza infantil". 
No encalço dessa pedagogia de ensino intuitivo, a instrução das crianças se configurou como sendo o modelo de educação da escola elementar. Diante disso, o presente estudo busca saber como o ensino de número foi proposto por esta perspectiva de escolarização primária. Para o alcance disso, segue a análise do livro elaborado por Pestalozzi, bem como a leitura crítica do manual de Calkins, também elaborado através das ideias pestalozzianas.

\section{A formação da ideia de Número na perspectiva intuitiva: as propostas de Pestalozzi e Calkins}

Após esta breve exposição dos princípios da pedagogia chamada de moderna ao longo do tempo, o estudo recai sobre a análise das fontes a fim de alcançar o objetivado. É importante dizer que as principais ideias da pedagogia de Pestalozzi podem ser lidas na obra Cómo Gertrudis enseña a sus hijos. Este livro busca nas entrelinhas responder e anunciar, através da sua produção e circulação, quais as finalidades e os meios da educação elementar pensados pelo seu autor. Neste documento, os princípios do método intuitivo foram apresentados, buscando mostrar quais noções e habilidades práticas são necessárias à criança para que ela adquira conhecimento através dos seus sentidos. Pestalozzi acreditava que a instrução emanava do interior da criança, das suas faculdades inatas. Essa instrução, diz ele, se dá de forma livre e espontânea quando a criança está em contato com as coisas: "Yo vi la fuerza de la naturaleza del hombre y de sus facultades en el juego más variado y más libre. [...] Aprendi com ellos à conocer a la fuerza efectiva de la intuición y á la conciencia sólida de los objetos que nos rodean" (PESTALOZZI, 1889, p. 13).

Além disso, o referido livro apresenta como aqueles conhecimentos poderiam ser oferecidos à criança através da ação do professor e/ou da mãe. Tais princípios norteadores e direcionadores da instrução elementar estão distribuídos em quatorze (14) cartas, do exemplar em análise. Juntas, essas cartas avultam o montante de 294 páginas, acrescidas outras dez páginas destinadas aos comentários do tradutor. A produção desse livro foi endereçada, pelo seu autor, ao seu amigo Géssner, editor de Zurique. 
As ideias presentes nessa obra de Pestalozzi expressam bem o seu método de ensino: “[...] me vino el pensamiento, de que el origen de nuestros conocimientos se encuentra en el número, la forma y la palabra, y me pareció que una luz enteramente nueva iluminaba mis investigaciones" (PESTALOZZI, 1889, p. 111, grifo do autor). Para ele, o número, a forma e a palavra são os pilares de sustentação e origem de todo conhecimento do homem. Ele chegou a esta conclusão quando apresentou para uma criança um objeto pela primeira vez. A princípio, esse objeto pareceu confuso aos olhos da criança, pois se outra pessoa solicitasse informações sobre tal objeto ela teria dificuldades para responder. Pestalozzi concluiu que essa dificuldade manifestada pela criança, nos primeiros contatos dela com as coisas, é algo normal, pois ela não tinha aprendido a fazer o seguinte exame: “1. Quantos são os objetos que estão a sua vista e quantas espécies? 2. Que aparência tem ele? qual a sua forma? qual o seu contorno? 3. Como se chamam? Como pode representar esse objeto por um som? por uma palavra?" (PESTALOZZI, 1889, p. 111, tradução nossa).

Percebe-se, pelo apresentado, que os três momentos do exame da pedagogia de ensino intuitivo são número, forma e palavra. No entanto, este ato analítico de cada coisa só tem êxito se o examinador possuir três faculdades essenciais. Primeiro, o indivíduo deve saber identificar, numericamente, a quantidade dos objetos que estão no alcance da sua vista. Segundo, o examinador necessita ter conhecimento da forma de diferentes objetos para saber distingui-los em concordância às suas particularidades. Terceiro, o sujeito precisa identificar cada coisa através do nome. Em linhas gerais, o educador suíço chegou à conclusão de que todos os objetos concretos são necessariamente representados pelo número, pela forma e pelo nome. Foi partindo desta consideração que Pestalozzi sistematizou sua pedagogia ancorada no ensino intuitivo.

Cumpre registrar ainda que a lógica sobre a qual esse método atua se inscreve na passagem da visão sincrética para sintética. E, mais ainda, a logicidade deste modo de ensinar também se coloca no processo analítico das observações das coisas e do seu ato experimental, quando esse processo segue a marcha da intuição para definição; do concreto para o abstrato; do simples para o complexo. É uma forma de ensinar que desloca a criança da passividade escolar para o campo da experimentação, da prática, da atividade, da exploração do conhecimento. 
A pedagogia do ensino intuitivo busca superar a inércia e a passividade do alunado. Ela propõe um ensino analítico no qual a criança é convidada a agir. A criança só aprende fazendo, experimentando, exercitando, sentindo. O que pressupõe fazer com que o aprendizado seja ativo. Sendo assim, esse é um método pedagógico que conduz o saber escolar por meio do ensino ativo. Para Souza (2000, p. 12), essa forma de ensinar se constituiu no núcleo principal da renovação pedagógica em tempos de modernização da escola primária. Ao longo do tempo, a pedagogia de ensino intuitivo passou a ser comumente chamada de pedagogia moderna.

Afinal, como se desenvolve na criança a ideia de número, segundo esses princípios do método intuitivo elaborado pelo pedagogista suíço?

A partir do que está registrado na carta VIII da obra Cómo Gertrudis enseña a sus hijos, intitulada El Numero, espero obter informações que permitam levantar resposta. A escrita da referida carta se inicia com seu autor fazendo a seguinte ressalva: "El tercer medio elemental para obtener nuestros conocimientos es el número" (PESTALOZZI, 1889, p. 175, grifo do autor). Pergunta-se: Como assim, o número sendo o terceiro meio elementar do nosso conhecimento se, no exemplo citado, o próprio Pestalozzi começou perguntando pelo número, depois pela forma e, por fim, pela palavra? De fato, essa lógica da organização do livro em análise pode até provocar uma falsa interpretação dos principais dispositivos metodológicos que condicionam os ensinamentos da escolarização da criança. No entanto, a logicidade interna do livro evidencia que os conhecimentos elementares se davam primeiro pela palavra, depois pela forma e em terceiro pelo número. Mas, isso não desvia o foco inicial.

No tópico referente ao ensino elementar do El Numero, distribuído entre as páginas 175 a 184, são encontrados os direcionamentos para a aquisição da ideia de número e da Aritmética. Durante a sistematização de um plano de instrução, Pestalozzi apontou que o som e a forma levam por muitas das vezes, e de diversas maneiras, o indivíduo ao germe do erro e da ilusão. Entretanto, esse germe não afloraria através da ideia de número. Para ele, a arte de identificar o quantitativo das coisas vistas na natureza era uma arte infalível devido ao meio pelo qual se representa cada coisa por um número, e que esse número tem único nome e símbolo particular para representá-lo (PESTALOZZI, 
1889). Por assim pensar, ele defendia o princípio de que, seguindo esta proposta, as noções claras de número seriam afloradas intuitivamente na inteligência da criança.

Nesta direção, Pestalozzi elaborou alguns caminhos que ele classifica como sendo aqueles mais simples e progressivos, cujo propósito é conduzir a criança para as noções claras de número. Antes disso, ele assinala:

Yo estoy convencido, en efecto, de que el arte de calcular, llevado aún á sus últimos límites, no puede ser un verdadeiro medio de ilustración, esto es, un medio de adquirir nociones claras é ideas perspicuas, sino com la condición de desenvolverse en el espíritu humano en la misma gradación en que se desarrolla desde su punto de partida en la naturaliza. (PESTALOZZI, 1889, p. 176)

De acordo com a citação, fica compreendido que a arte de calcular não se pratica por meio ilustrativo/imaginário, faz-se necessário seguir a mesma graduação de desenvolvimento do espírito humano e tomar como ponto de partida a natureza. Ou seja, como cada objeto/fato/coisa do mundo exterior tem nome e forma, logo este mesmo objeto/fato/coisa pode ser tomado como exemplo para expressar a ideia de número. Para Pestalozzi (1889, p. 176, tradução nossa), "a Aritmética, em si, traz em toda sua origem a habilidade de agregar e retirar unidade/número de várias coisas da natureza". Para ele, a arte de conhecer um objeto a partir da representação de quantidade (do número) não é nada mais nada menos que uma abreviação do cálculo. É válido considerar que o ensino de número "[...] se puedan aprovechar todas las ventajas que pueden proporcionar en general á la enseñanza una psicología profunda y el conocimiento más vasto de las leyes del mecanismo del mundo físico (PESTALOZZI, 1889, p. 176). Desta forma, Pestalozzi chamou a atenção para a força e o cuidado de ensinar o último meio elementar da instrução: o número.

Nessa direção, fica entendido que a ideia elementar do número não pode ser formada na mente da criança da mesma forma que se ensina Aritmética. Isto é, segundo o modo de instruir elaborado por Pestalozzi, o ensino de Aritmética é apenas uma abreviação dos números. Abreviação essa que recai sobre a arte de calcular. Por assim pensar, ele diz que a conceituação de número deve ser “[...] grabada profundamente y con gran cuidado [...], y todo progresso ulterior de esta última debe fundarse en el 
conocimiento profundo que ha adquirido el espíritu de las relaciones reales, que son la base de todo cálculo" (PESTALOZZI, 1889, p. 177). Tendo em vista que o cálculo é apenas uma abreviação do número, percebe-se, contudo, que as coisas presentes na natureza seriam as mais proveitosas e eficazes representações claras que expressam a ideia de número. Para realçar este entendimento, é oportuno escutar o próprio Pestalozzi, que assim diz:

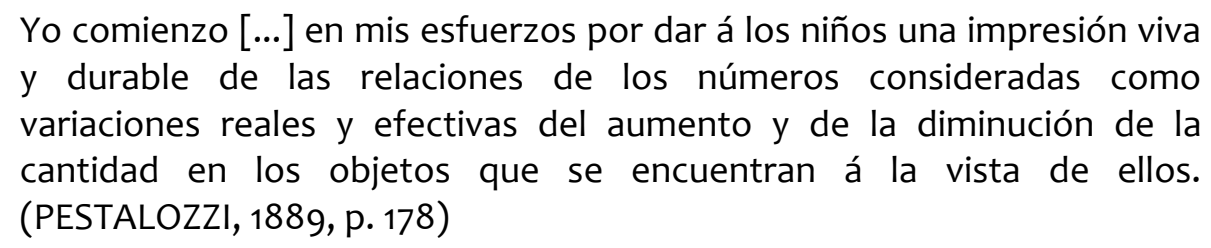

Pelo citado, observa-se que a exposição de objetos para a criança explorar suas faculdades se configura como o caminho pelo qual a ideia de quantidade tende a ser formada. Segundo a pedagogia de Pestalozzi, não fazia sentido algum para a criança mostrar-Ihe o simbolismo arábico, haja vista que este procedimento estaria afastando-a da experiência concreta, perceptiva e sensível de atribuir significados às coisas que estão diretamente ao alcance dela. A defesa desta perspectiva encontra sustentação na premissa de que esses significados conduzem a inteligência da criança em direção à sua capacidade natural de raciocinar, de comparar, de medir, de contar. Em outras palavras, apresentar à criança os símbolos numéricos sem o seu sentido real de quantidade pressupunha que ela não compreende o significado de tal simbolismo. Isso permite dizer que mostrar e fazer a criança inculcar as palavras um, dois, três, quatro..., não traz sentido algum para o aprendizado deste saber escolar.

Segundo Eby (1978, p. 393) "foi esse costume insensato que provocou o acerbo de Pestalozzi e o levou a estabelecer o elo entre o objeto concreto para a enumeração". Derivando isso, talvez seja possível dizer que aprender número no modelo de instrução idealizado por Pestalozzi poderia ser chamado de "impressão viva da concretude". Esta pressuposição ganha significado quando ele propõe que o ensino de número seja o seguinte: um livro, dois lápis, três bolas, quatro maçãs... Percebe-se que ideia de número é 
expressada e experimenta de modo sensível, perceptivo e intuitivo, os quais possibilitam à criança aprender e apreender cada significação numérica. Assim, estas seriam as bases cuja formação da ideia de número emanaria pela clareza no experimentar e precisão no pensar. Pode-se dizer que esta seja a principal premissa que caracteriza a pedagogia do intuir para o ensino deste saber aritmético elementar. Por outro lado, diz Pestalozzi (1889, p. 36) que “todo depende de la psicologia de la forma de la enseñanza”.

Continuando com a análise, ainda na carta VIII, o autor salienta alguns passos metodológicos a serem seguidos para a utilização dos objetos no ensino de número. 0 primeiro desses passos, diz que após dispor os objetos à criança para que ela pudesse observar e/ou manipular, dever-se-ia apontar para o objeto e dizer número um, dois, três, ... até dez, de modo que cada grupo de objeto represente a quantidade indicada. De início, Pestalozzi indica que ensinar número para a criança parte sempre da unidade um, depois dois, em seguida três e assim sucessivamente. "En seguida les hago encontrar esas mismas relaciones, contando con los dedos, ó con garbanzos, piedrecitas y otros objetos que se tienen á la mano" (PESTALOZZI, 1889, p. 178). Com o propósito de exercitar e testificar a aquisição da ideia de número, o pedagogista aconselha a pegar um objeto e perguntar para a criança: tenho nas mãos muitos objetos? Se a criança de fato estivesse familiarizada com tal ideia responderia: não, tem apenas um. Em seguida levantaria dois objetos e tornaria a perguntar. A resposta dada pela criança é que garante a marcha do aprendizado e do avanço nos estudos. Seguindo desta forma, a aprendizagem de número se dava por meio da familiarização intuitiva do cálculo. Compreenda essa familiarização com cálculo no sentido de diferenciar os objetos pela sua quantidade: muitos objetos ou poucos objetos, afinal cada grupo de objeto é representado pela unidade um tantas vezes.

Ao seguir os princípios de Pestalozzi presentes na obra Cómo Gertrudis enseña a sus hijos, nota-se que a formação da ideia de número tem início com o uso dos objetos concretos. Tal procedimento busca estimular a percepção sensorial da criança. Além disso, o contato dela com os objetos possibilita o discernimento claro de cada percepção através da palavra que representa a quantidade das coisas vistas e/ou tocadas. Por fim, o livro sugere a prática de exercícios de modo a fixar na memória da criança cada passo da aprendizagem de número. Neste sentido, é oportuno concordar com Valente (2012), 
quando ele apontou que na pedagogia de ensino intuitivo "[...] a conceituação de número passa a quantidade a ser sentida" (grifo do autor). Por outro lado, é importante considerar que essa quantidade passa a ser sentida não por um simples tocar dos objetos, mas pela própria percepção das impressões sensíveis das coisas ao alcance da criança. A percepção exercita a criança a aguçar sua observação, seu poder de raciocinar, de comparar, de julgar e de enumerar cada coisa como unidade.

Além disso, a obra de Pestalozzi revela que outro meio para a criança gravar profundamente na inteligência a ideia de número encontra-se na divisão das palavras em sílabas e em letras. A partir de uma frase ou de um pequeno texto o procedimento metodológico a ser seguido seria: "quantas letras têm essa palavra? E depois, quantas sílabas?" (PESTALOZZI, 1889, p. 178, tradução nossa). Agindo assim, a criança se familiariza com a ideia de quantidade/número. De modo análogo, ela também está adquirindo "[...] valor intrínseco de los números antes que procedan á hacer uso de ellos, sin tener á la vista el fondo de la intuición que les ha servido de base" (PESTALOZZI, 1889, p. 179).

Já com relação à obra Primeiras Lições de Coisas: manual de ensino elementar para uso de pais e professores, do norte-americano Norman A. Calkins, tudo indica que a ideia de número projetada por Pestalozzi ganhou outros reempregos, outras interpretações, outros sentidos - isto é, outras modalidades de apropriação. Com o título Primary object lessons for training the senses and developing the faculties of children. A manual of elementary instruction for parentes and teachers ${ }^{10}$, publicado em 1861 nos Estados Unidos, esse manual foi traduzido em 1881 , na sua $40^{a}$ edição, para o português pelo então legislador provinciano Rui Barbosa ${ }^{11}$. Entretanto, o manual só foi publicado em 1886.

\footnotetext{
${ }^{10} \mathrm{~A}$ afirmação de que esse manual foi composto pelo método intuitivo pode ser verificada no preâmbulo do exemplar traduzido por Rui Barbosa. Somam-se a isso, os escritos de Gladys Mary Teive Auras (2004), os quais apontam que "em 1846 [Norman Calkins] fundou [no EUA] a revista 'Student', dedicada à divulgação dos métodos educativos renovados, em especial, o método pestalozziano".

${ }^{11}$ O manual de Calkins foi apresentado na Exposição Universal de Filadélfia, realizada em 1876, sendo recomendado por Ferdinand E. Buisson em seu relatório ao governo francês como a melhor coleção de lições de coisas já elaborada, motivando numerosas traduções, além da língua portuguesa, destacando-se uma versão japonesa, em 1877, e duas versões para o espanhol, em 1872 e 1879. A primeira edição americana desse manual é de 1861, sendo refundida e ampliada em 1870, recebendo o título de Primeiras lições de coisas e atingindo, em 1884, sua $40^{a}$ edição. As referências aqui apresentadas são da publicação de 1950, coordenada pelo Ministério da Educação e Saúde, no volume 13 das obras completas de Rui Barbosa (VALDEMARIN, 2004, p. 118).
} 
Atuante ativo nas questões políticas, econômicas, sociais e educacionais de seu tempo, Rui Babosa de Oliveira era o que hoje se pode chamar de um soteropolitano nascido em 1849. Anos depois, em 1864, ele ingressou na Faculdade de Direito de Olinda. Porém, recebeu o título de bacharel e doutor em Ciências Sociais e Jurídicas na Faculdade de Direito de São Paulo, onde concluiu os estudos de direito no ano de 1870. Ao regressar para o estado baiano, ele atuou como advogado. Em 1877, foi eleito deputado da Assembleia da Bahia e, no ano seguinte, deputado da Assembleia da Corte/RJ. Não querendo fazer uma cronologia da vida de Rui Barbosa, basta resumir dizendo que este personagem da intelectualidade brasileira lutou com grande maestria em diferentes âmbitos sociais para condicionar o seu país ao mesmo nível de modernização em que outras nações já se encontravam. Em 1923, o Brasil perdeu mais uma matéria humana de carne e osso, mas o seu legado educacional permaneceu ativo.

Reduzir os ideais reformistas de Rui Barbosa para a sociedade brasileira tomando apenas as questões da educação seria, e é, renegar suas principais lutas contra "a escravidão, as barreiras que impediam a imigração, o voto controlado pelo governo, a centralização do poder, a moeda e o crédito" (MACHADO, 2002, p. 80). Tais lutas visavam o caminhar da nação em direção à modernização. Para isso, fez-se necessária uma nova proposta de reforma da instrução oferecida pelo Estado brasileiro. Uma das iniciativas tomadas por este intelectual brasileiro foi justamente a tradução da obra de Calkins, a qual se tornou o manual pedagógico “[...] para professores mais difundido e usado no Brasil, durante os anos finais do Império e grande parte da primeira República (18891930)" (BASTOS, 2000, p. 85).

Segundo Bastos (2000, p. 86), Rui Barbosa fez a referida tradução por ele ter enxergado a necessidade de um manual pedagógico que colocasse os professores brasileiros em contato com a teoria e a prática das técnicas de Pestalozzi. Realizando uma leitura interna deste exemplar para a análise, fica em evidência que o manual é composto por dezesseis (16) temas das Lições de coisas, distribuídas em 616 páginas, sendo que duas foram destinadas à errata do tradutor ${ }^{12}$. Dentre as páginas que compõem a obra, nota-se que 249 envolvem temas matemáticos: Forma (p. 46-160); Número (p. 237-328); Tamanho

\footnotetext{
12 Há também o quantitativo de 18 páginas que representam o preâmbulo do tradutor, bem como a tradução do prólogo de outras edições do manual.
} 
(p. 328-362); Desenho (p. 363-370); e Tempo (p. 371-375). Este quantitativo corresponde a um percentual aproximado de 40,4\% das páginas do livro. Isso mostra a relevância que ganhou o ensino de Matemática nas técnicas de Pestalozzi, as quais foram apropriadas por Calkins.

Os textos e exercícios que compõem a obra Primeiras Lições de coisas dividem-se em cinco novas matérias, as quais não foram trabalhadas nas edições precedentes. Essas matérias são identificadas como: Educação doméstica dos sentidos; Exercícios para incutir o hábito de pensar; Do tempo; De como ensinar os sons da linguagem; e Qualidades das coisas. Durante o percurso dessas matérias, esperava-se que fosse desenvolvida na criança a capacidade da aquisição do conhecimento pela "Forma, Cor, Número e Nome" dos objetos. Ainda na análise do manual pedagógico, observa-se que a sua capa é composta de informações que ressaltam a importância da sua publicação. Há um texto que expõe a sua aprovação unânime pelo Conselho Superior da Instrução Pública da Bahia, pelo Conselho Diretor da Corte e a sua adaptação pelo Governo Imperial. Ainda na capa, há um texto que salienta a relevância das lições de coisas, enfatizando que se deve apresentar ao menino, antes dos vocabulários, as coisas, e antes dos nomes, as ideias. Fica compreendido que a criança deveria ser ensinada a observar, a executar e a refletir sobre as coisas. Por isso, esse manual acabou sendo visto, pelos dirigentes educacionais da época, como um dos dispositivos responsáveis pela divulgação e orientação do método intuitivo no solo brasileiro.

As lições de coisas trazidas nesse manual podem ser compreendidas como uma proposta metodológica de ensino caracterizada pelo aspecto, pela realidade, pela reflexão, pela intuição, pela faculdade da observação e pela experimentação. Ao serem apresentados à criança, os objetos solicitam a manifestação das aptidões sensíveis e mentais. São estas faculdades, a de percepção e a de reflexão, que põem a inteligência em contato real com a natureza. A fundamentação do método de ensino intuitivo "[...] consiste na colocação de fatos e objetos para serem observados pelos alunos, criando situações de aprendizagem [...]" (VALDEMARIN; SOUZA; ALMEIDA, 1998, p. 70). O ensino pelas coisas deveria ser aplicado por meio da manipulação e observação dessas. $O$ ensino intuitivo é condicionado também pela marcha das lições de coisas. 
Como já é sabido que Calkins foi um seguidor das ideias pestalozzianas, basta apresentar alguns dos nove princípios fundamentais das lições de coisas trazidos no manual de Calkins;

1. É pelos sentidos que nos advem o conhecimento do mundo material. Os primeiros objectos onde se exercem as nossas faculdades, são as coisas e os fenômenos do mundo exterior;

2. A percepção é a primeira phase da inteligência, [...];

5. algumas das energias mentaes são tão activas e quase tão vigorosas no menino, quanto no homem: taes a sensação, a percepção, a observação, a comparação, a simples retentiva e a imaginação;

9. O processo natural de ensinar parte do simples para o complexo; do que se sabe, para o que se ignora; dos factos, para as causas; das coisas, para os nomes; das idéas, para as palavras; dos princípios, para as regras $^{13}$. (CALKINS, 1886, p. 1-3)

Estes foram os princípios que certamente garantiram a logicidade metodológica de cada tema presente no manual. Entre os temas, apenas dois momentos foram destinados para a formação da ideia elementar do número: o primeiro encontra-se na parte que trata da educação doméstica dos sentidos (p. 29-32); o segundo pode ser visto no tema Número (p. 237-328) 14 $^{14}$ A mesma racionalidade lógica de ensinar a ideia de número que aparece no primeiro momento é contemplada no tema Número só que de forma mais abrangente. Por este motivo, esta análise se deu a partir do tópico Número.

De início, é possível perceber que o norte-americano buscou orientar a formação da ideia de número utilizando a mesma dinâmica proposta por Pestalozzi: o contato com os fatos/coisas/objetos do mundo exterior. Dizendo isso de outro modo, constatam-se, de início, similitudes entre os processos metodológicos pestalozzianos e os do norteamericano. Por outro lado, observa-se que há também no manual de Calkins o acréscimo de alguns procedimentos metodológicos, o que permite uma sucinta compreensão da apropriação de Pestalozzi por Calkins, no que se alude ao ensino de número. Pois, como

\footnotetext{
${ }^{13}$ Optou-se pela conservação da grafia.

14 Embora esse tema foi explorado neste quantitativo de páginas, vale ressaltar que tais páginas contemplam os seguinte tópicos: idéias elementares de numero; primeiras idéias de algarismos; sommar; diminuir; ordem dos numeros; sommar sem contar; numeração e notação dos numeros; da addição; da subtracção; da multiplicação; frações. Preservei a grafia original dos tópicos.
} 
já foi mencionado, as modalidades de apropriação manifestam-se nos significados, nos usos, nas interpretações que o indivíduo atribui àquilo que é recepcionado.

Para o norte-americano, a noção de número era formada quando a criança discernia as coisas pela forma e pela cor. Este ponto se configurou na proposta deste pedagogo como sendo "[...] o ponto de partida no aprender a numeração" (CALKINS, 1886, p. 237 , grifo do autor), embora a criança não se tenha dado conta de que estava emitindo juízo entre dois ou mais objetos. A instrução elementar proposta pelo manual para o ensino de número assegura que os objetos são princípios dos números concretos, ou seja, "o bom exito do ensino elementar, neste assumpto, depende da exhibição real dos objetos" (CALKINS, 1886, p. 237). Contando os objetos como lápis, moedas, botões, bolas, livros, maçãs etc., o conhecimento de número caracterizava-se através da percepção imediata e espontânea de enumerá-los.

Afinal, como a criança enumera algo sem saber como representa esse algo quantitativamente? A resposta para isso talvez seja apresentada a seguir.

Nas lições para desenvolver a ideia de número, Calkins propõe três (3) passos para ensinar a criança a contar: $1^{\circ}$ passo - formaria ideias de um a nove; $2^{\circ}$ passo desenvolveria ideias de dez a dezenove; $3^{\circ}$ passo - de vinte a vinte e nove. O procedimento metodológico sugerido pelo pedagogista norte-americano configura-se por meio da disposição de diversos objetos ${ }^{15}$ concretos (moedas, botões etc.), distribuídos da seguinte maneira:

Fonte: CALKINS, N. A. Primeiras Lições de coisas: manual de ensinamento elementar para uso dos paes e professores. Rio de Janeiro: Imprensa Nacional, 1886, p. 240.

\footnotetext{
${ }^{15}$ Soma-se a isso o emprego de traços na pedra. Essa pedra poderia ser a ardósia - material em que o aluno escrevia os tópicos ensinados -, atualmente chamada de caderno. Indicava-se também o uso do contador. Esse objeto era formado por arames e por esferas. Assim, ao que tudo indica perece que o manual de Calkins estava se referindo ao ábaco.
} 
No manual, evidencia-se a assertiva de que a ideia de número emerge na mente da criança quando ela conta os objetos: dizendo um, e indicando o objeto que representa o número um. Em seguida, aconselha a indicação dos objetos da segunda linha, pronunciando um, dois. Passando para a linha três, aponta-se para os objetos desta, contando: um, dois e três... A dinâmica segue prosseguindo gradativamente de modo que a criança conte desembaraçadamente até nove. A mesma racionalidade lógica também é adotada no segundo e no terceiro passo. Evidencia-se assim que o norte-americano segue o mesmo princípio pestalozziano: ensinar número associando-o às coisas/objetos concretos. A criança não deve apenas aprender a contar, torna-se necessário que ela adquira e professe o verdadeiro significado que cada palavra expressa. Para isso, o caminho a ser adotado segue a dinâmica deste exemplo: um botão, dois lápis, três moedas... Isto é, a quantidade é também expressada pela concretude das coisas.

Outro caminho metodológico evidenciado no manual é o exercício da conversação. Este é também um dos princípios da pedagogia do ensino intuitivo. O jogo de perguntas e respostas a partir de objetos deve ser visto não como uma prática de catecismo, mas como uma ginástica mental que requer do indivíduo a sua capacidade analítica de marchar da visão sincrética para a sintética. A exemplo, o manual sugere tais perguntas: quantos olhos tendes?; quantos pés?; quantas mãos?; quantos dedos em cada mão?; e, assim, sucessivamente. De outro modo, o próprio Calkins (1886, p. 244) alerta que só se pode avançar com estes estudos "[...] segundo a capacidade e aproveitamento dos alunos".

O ensino de número proposto pelo manual se dava através de objetos concretos, seguindo a marcha gradativa de modo a respeitar o "[...] espírito infantil e os processos por que adquire o saber [...]" tendo o cuidado de não "[...] obter das creinças que vençam muito terreno de uma vez" (CALKINS, 1886, p. 270). Esta passagem revela algumas (re)significações e reempregos dos mesmos procedimentos metodológicos que Pestalozzi adotou na sistematização da sua proposta de ensino. O pedagogo suíço chamou a atenção para que a criança tivesse atividades convenientes a cada idade e capacidade intelectual, de modo a "no omitir, por una parte, nada de lo que él es enteramente capaz de aprender, $y$, por otra, para no recargar ni perturbar su inteligencia con estudios que él no es capaz de compreender" (PESTALOZZI, 1889, p. 24-25). 
Por outro lado, nota-se também que no manual de Calkins a representação quantitativa dos objetos seria formada, de início, através da pronúncia e escrita. Ou seja, a criança não teria visto a representação simbólica que ilustra a palavra um, dois, três, quatro... O manual propôs isso no segundo momento para desenvolver a ideia elementar de número. Este novo passo caracteriza-se por ensinar à criança as noções de algarismos. Noutros termos, pode-se dizer que esta lógica acompanha a representação simbólica da palavra de quantidade um, dois, três..., com as figuras $^{16} 1,2,3 \ldots$

Esse segundo momento proposto por Calkins seguiu a mesma dinâmica que o passo anterior, subdivisão em passos. No $1^{\circ}$ passo - abordaria os símbolos de 0 a 9. Neste passo, a criança aprende o significado de zero e o símbolo que lhe representa (0). No $2^{\circ}$ passo - versaria sobre os números de dez a dezenove (10 a 19). O $3^{\circ}$ passo - figuraria os algarismos que representam de vinte a vinte e nove (20 a 29), em seguida o aluno abandonaria o auxílio dos objetos e aprenderia a contar de zero (0) a noventa e nove $(99)^{17}$. No $4^{\circ}$ passo - já seria destinado para o ensino das centenas (100 a 999). Por assim proceder, o manual de Calkins evidencia que o ensino de número ganhou outros sentidos e diferentes modos de expressar a ideia de quantidade tendo em vista a pedagogia pestalozziana. Esta afirmação se justifica porque não foram identificadas na obra do pedagogista suíço etapas a serem seguidas para representar a noção de número como algarismos simbólicos.

Diante destes dois momentos propostos pelo manual, ora pronunciado ora representado por algarismo ou símbolo, um procedimento metodológico chamou a atenção. Além de ter oferecido exercícios práticos para familiarizar a criança com o conceito de número, o manual também aconselha o professor a não ficar utilizando apenas a sequência natural dos números $(0,1,2,3,4 \ldots)$. O livro recomenda escrever esses algarismos fora da ordem $(4,1,3,0,2 \ldots)$. Esta racionalidade lógica tinha como intento que a criança desenvolvesse o bom manejo com os números. Ou seja, os princípios do método intuitivo apropriado por Calkins não pressupunham que a criança decorasse a sequência

\footnotetext{
${ }^{16}$ Neste tópico de estudo o próprio manual classifica a palavra figura como sendo algarismo (CALKINS, 1886, p. 249, nota de rodapé).

${ }^{17}$ Este avanço na formação de ideia de número, que ia de zero a noventa e nove, se daria ao passo em que as crianças conseguissem apreender a lógica de que na primeira linha os números iam de 0 a 9 . Na segunda linha os números iam de 10 a 19, e assim por diante. Mostrar para a criança que as linhas que se sucedem são apenas a conservação dos números da primeira linha, acrescentando na frente de cada um desses o algarismo um, dois, três, quatro... até nove, que é quando se formará a linha dos noventa.
} 
numérica, mas que o aluno adquirisse o aprendizado da noção de algarismo (número) também fora da ordem.

Por assim seguir, pode-se inferir que a pedagogia de ensino intuitivo propunha outros meios para adquirir o conhecimento de número, os quais rompiam com o ensino de cor. A criança iria expor suas habilidades/familiaridades com a arte de contar quando os algarismos fossem postos também em ordem distintas. Este postulado talvez se configure como mais um marco na ruptura metodológica para o ensino de número proposto pela pedagogia de ensino intuitivo: não era mais indicado decorar a sequência numérica, era agora recomendado que a criança aprendesse cada número mentalmente de forma significativa. Isto é, um aprendizado ligando os números aos objetos e despertando a percepção quantitativa das coisas não mais sequenciadas.

Soma-se a essa racionalidade lógica proposta pelo método intuitivo, o princípio da conversação apresentado no livro de Pestalozzi (1889). De outra parte, cumpre assinalar, noutros termos, que a conversação não pode ser vista e compreendida apenas como mais uma prática verbalista. Pelo contrário, esse princípio ansiava que a criança transformasse em palavras as suas percepções sensíveis e imediatas das coisas que eram formadas na sua memória. A criança, por meio dialético, tende a transformar suas intuições obscuras em noções claras, passando do que ela sabe para o que ela ignora, do simples ao complexo, das coisas para as palavras. Este mesmo posicionamento de estimular as capacidades naturais da criança também foi apresentado nas propostas de instrução elementar de Pestalozzi e Calkins.

\section{Para concluir, alguns apontamentos}

Pelo estudo aqui realizado não se configura uma tarefa fácil apresentar algumas palavras finais, tendo em vista o desafio de analisar obras de grandes educadores. Por outro lado, as questões aqui levantadas solicitam respostas. Neste sentido, ficou percebido que para o ensino de número, os procedimentos metodológicos do educador suíço foram apropriados pelo norte-americano na composição de seu manual. Para ambos os autores, ensinar número na perspectiva intuitiva parte de uma variedade de 
objetos concretos ao alcance da criança para que ela, através das experiências dos sentidos, marche da intuição para a definição. O conhecimento de número emerge no momento empírico - na experiência sensorial do ver e do tocar. Este contato com o concreto estimula na criança suas faculdades de percepção e sensação, de modo a excitar as ideias por meio do raciocínio. Ao agir assim, a criança também desenvolve a capacidade de julgar a quantidade/número das coisas. Deste modo, a ideia de número seria tanto sentida quanto gerada.

Seguindo os princípios intuitivos, pode-se afiançar que não seria mais aceitável instruir a criança como se a memória dela fosse um "depósito de informações alheias". Isso se caracterizou como um processo de ensino que possibilita à criança o pensar, estimulando o desenvolvimento de suas faculdades inatas. Esta dinâmica faz da instrução um momento individual de cada criança. Ela própria precisava ser conduzida e estimulada a experimentar os objetos, almejando que suas ideias adquirissem significados. Como consequência, essa dinâmica manteria viva a atenção da criança para que ela viesse a ter a capacidade de julgar e comparar os objetos. Por assim seguir, a criança estaria trabalhando em um processo de ação e comparação. É nesta perspectiva que a conceituação de número seria uma ideia a ser gerada pela própria ação e atividade motora e cognitiva da criança, e não de outrem.

Cumpre dizer que a experiência sensorial para a criança aprender número seria um processo ativo. Isto é, as faculdades da criança de discriminar, analisar, julgar, comparar e abstrair estariam comprometidas na experiência sensorial. A criança estaria identificando a qualidade e particularidade dos objetos dispostos para o momento empírico. Assim, sua mente permanecia especialmente ativa. Neste processo ativo, ensinar número, pelas propostas de Pestalozzi e Calkins, iniciava-se sempre da aprendizagem da unidade um. Pois, de acordo com o método pestalozziano, dois, três, quatro... são apenas quantidades que contém um tantas vezes. Porém, as diferenças observadas entre ambas as propostas foram: em Pestalozzi o ensino inicial de número deveria ir de um a dez, já em Calkins iniciava do um indo até nove; em Pestalozzi não apareceu o momento em que a criança aprenderia os algarismos, já em Calkins este tipo de ensino seria trabalho no segundo momento; em Pestalozzi a ideia de número partiria através do exame da forma e da 
palavra dos objetos; já em Calkins, a conceituação de número seria trabalhada a partir do instante em que a criança discernisse as coisas pela forma e pela cor.

Olhando para os indicadores da história cultural e cogitando que ambas as propostas foram representações do modo intuitivo de instruir, talvez não seja muito dizer que apesar de serem dois documentos de natureza distinta, estas obras tiveram "[...] por objetivo anular-se enquanto discurso e produzir na prática comportamentos ou condutas tidos por legítimos e úteis" (CHARTIER, 1990, p. 135), buscando incorporar uma nova forma de ensinar número. De fato, essas obras tencionaram possibilitar que o saber de número passasse a ser sentido e a ser gerado na prática experimental da criança. Isso porque o estudo apresentado configurou a assertiva de que a proposta intuitiva enxergava número como um saber elementar útil, e que poderia ser sentido e gerado cotidianamente a partir dos objetos ao redor da criança - nos seus espaços de vivência. Assim, ensinar número na vaga pedagógica intuitiva, idealizada por Pestalozzi e apropriada por Calkins, pressupôs enumerar algo concreto que esteja ao encalce dos sentidos da criança.

Pelo visto e lido, é importante considerar ainda que o contexto do qual as obras se destacaram foi aquele em que as ideias internacionais ventilavam o ideário de uma pedagogia moderna. Quando se diz que as ideias ventilavam não se quer pronunciar que foram ideias pairadas no ar. Pelo contrário, elas tiveram como referencial os experimentos realizados nas escolas de Pestalozzi. Posteriormente, elas passam a fazer parte das discussões sobre os avanços pedagógicos realizados por países europeus e, de modo mais particular, nos Estados Unidos. Esses avanços foram exibidos e classificados nas vitrines do progresso oitocentista - as Exposições Universais (MONARCHA, 2009, p. 29). Vitrines estas que conferiram ao manual de Calkins um certo reconhecimento pela sua composição metodológica. 


\section{Referências}

AURAS, Gladys Mary Teive. Manual de lições de coisas de Norman Calkins: produzindo professores para tecer a República em Santa Catarina. In: CONGRESSO BRASILEIRO DE HISTÓRIA DA EDUCAÇÃO, 3, 2004. Paraná. Anais... Paraná: PUC/PR, 2004, p. 1-10.

BASTOS, Maria Helena Camara. Ferdinand Buisson no Brasil - pistas, vestígios e sinais de suas idéias pedagógicas (1870-1900). Revista da Educação, Pelotas, n. 8, p. 79-109, set. 2000.

BICCAS, Maurilane de Souza. Roger Chartier: contribuições para a história da educação. In: LOPES, Eliana Marta Texeira; FARIA FILHO, Luciano Mendes (Org.). Pensadores sociais e a história da educação II. Belo Horizonte: Autêntica Editora, 2012, p. 269- 296.

CALKINS, Norman Allison. Primeiras lições de coisas: manual de ensinamento elementar para uso dos paes e professores. Tradução de Rui Barbosa. 40. ed. Rio de Janeiro: Imprensa Nacional, 1886.

CHARTIER, Roger. A história cultural: entre práticas e representações. Tradução Maria Manuela Galhardo. Rio de Janeiro: Bertrand Brasil, 1990.

COSTA, David Antonio. A Aritmética escolar no ensino primário brasileiro: 1890-1946. 2010, 279f. Tese (Doutorado em Educação Matemática) -Pontifícia Universidade Católica de São Paulo - PUC/SP, São Paulo, 2010.

DARNTON, Robert. Edição e sedição: o universo da literatura clandestina no século XVIII. São Paulo: Companhia das Letras, 1992.

EBY, Frederick. História da educação moderna: teoria organização e práticas educacionais. Tradução de Maria Ângela Vinagre de Almeida; Nelly Aleotti Maia e Malvina Cohen Zaide. 5. ed. Porto Alegre: Editora Globo, 1978.

MACHADO, Maria Cristina Gomes. Rui Barbosa: pensamento e ação. Campinas: Autores Associados, 2002.

MONARCHA, Carlos. Brasil arcaico, escola nova: ciência, técnica \& utopia nos anos 19201930. São Paulo: Editora UNESP, 2009.

OLIVEIRA, Marcus Aldenisson. Antônio Bandeira Trajano e o método intuitivo para o ensino de Arithmetica (1879-1954). 2013. 142f. Dissertação (Mestrado em Educação). Universidade Tiradentes, Programa de Pós-Graduação em Educação, Aracaju, 2013.

PESTALOZZI, Johann Heinrich. Cómo Geetrudis enseña a sus hijos: fines y métodos de la éducacion del Pueblo. Cartas dirigidas a Gésser. Tradução José Tadeo Sepúlveda (versão chilena), 1889. 
PINHEIRO, Nara Vilma Lima. Escolas de práticas pedagógicas inovadoras: Intuição, Escolanovismo e Matemática Moderna nos primeiros anos escolares. 2013. $155 \mathrm{f}$. Dissertação (Mestrado em Ciências) - Universidade Federal de São Paulo, Programa de Pós-Graduação em Educação e Saúde na Infância e na Adolescência, Guarulhos, 2013.

RIBEIRO JÚNIOR, José. O Brasil monárquico em face das Repúblicas Americanas. In: MOTA, Carlos Guilherme (Org.). Brasil em perspectiva. 2. ed. Coleção Corpo e Alma do Brasil. São Paulo: Difusão Européia do livro, 1969, p. 147-162.

SOËTARD, Michel. Johann Pestalozzi. Tradução: Martha Aparecida Santana Marcondes; Pedro Marcondes e Ciriello Mazzetto. Recife: Fundação Joaquim Nabuco Editora Massangana, 2010.

SOUZA, Rosa Fátima. Templos de civilização: a implantação da escola primária graduada no Estado de São Paulo (1890-1910). São Paulo: Editora UNESP, 1998.

SOUZA, Rosa Fátima. Inovação educacional no século XIX: a construção do currículo da escola primária no Brasil. Cadernos Cedes. Campinas, ano XX, n. 51, p. 9-28, nov. 2000.

VALDEMARIN, Vera Teresa. Estudando as lições de coisas: a análise dos fundamentos filosóficos do Método de Ensino Intuitivo. Campinas: Autores Associados, 2004.

VALDEMARIN, Vera Teresa; SOUZA, Rosa Fátima; ALMEIDA, Jane. Soares. O legado educacional do século XIX. Araraquara: UNESP, Faculdade de Ciências e Letras, 1998.

VALENTE, Wagner Rodrigues. O que é número? Produção, circulação e apropriação da Matemática Moderna para crianças. Revista Boletim de Educação Matemática, v. 26, n. 44, Rio Claro, 2012. Disponível em: <http://www.scielo.br/scielo.php?pid=S0103636X2012000400014\&script=sci_arttext >. Acesso em: 15 ago. 2013. 